\title{
Fluconazole Resistance Candida albicans in Females With RecurrentVaginitis and Pir1 Overexpression
}

\author{
Zahra Nasrollahi ${ }^{1}$; Mohammad Hossein Yadegari ${ }^{2, *}$; Shahla Roudbar Mohammadi ${ }^{1}$; Maryam \\ Roudbary $^{3}$; Maryam Hosseini Poor ${ }^{2}$; Fatemeh Nikoomanesh ${ }^{1}$; Masumeh Rajabi Bazl ${ }^{4}$ \\ ${ }_{1}^{1}$ Religion and Medicine Research center, Qom University of Medical Sciences, Qom, IR Iran \\ 2 Department of Mycology, Faculty of Medicine, Tarbiat Modares University, Tehran, IR Iran \\ ${ }^{3}$ Department of Parasitology and Mycology, School of Medicine, Iran University of Medical Sciences, Tehran, IR Iran \\ ${ }^{4}$ Department of Clinical Biochemistry, Faculty of Medicine, Shahid Beheshti University of Medical Sciences, Tehran, IR Iran \\ ${ }^{*}$ Corresponding author: Mohammad Hossein Yadegari, Department of Mycology, Faculty of Medicine, Tarbiat Modares University, Tehran, IR Iran. Tel: +98-82883883, Fax: +98-2182883019, \\ E-mail:yadegarm@modares.ac.ir
}

Received: June 22, 2014; Revised: November 11, 2014; Accepted: November 30, 2014

Background: Some genes may be associated with Candida albicans resistance to azoles. Pir1 gene is described as responsible to induce resistance in C. albicans.

Objectives: The current study aimed to find the relationship between fluconazole resistance and Pir1 protein (Pirlp) overexpression in the females with recurrent $C$. albicans vaginitis requiring longer fluconazole therapy.

Patients and Methods: A total of 521 vaginal samples were obtained from the females with C. albicans vaginitis. The azole susceptibility phenotype was determined according to the Clinical Laboratory for Standards Institute (CLSI) protocol for disk diffusion method and inhibition zone for fluconazole. Expression of pir1 gene and fluconazole -resistance were evaluated using polymerase chain reaction (PCR) in C. albicans.

Results: In the 52 isolates, 49 (94\%) were resistant to fluconazole. Overexpression of Pir1 gene was detected in 47(96\%) fluconazole-resistant C. albicans isolates.

Conclusions: The findings show fluconazole -resistance in C. albicans isolates with overexpression of Pir1p.

Keywords: Vaginitis; Fluconazole-Resistance; PCR; Pir1; Candida albicans

\section{Background}

Candida albicans is an opportunistic pathogen causing invasive infections and vaginitis in immunocompromised patients (1). Approximately two-thirds of females experience candida vaginitis at least once during their lifetime and $50 \%$ of them experience vulvovaginal candidiasis more than once. Candida albicans cause the majority of vaginal candidiasis cases (2). The resistance of $C$. albicans species to antifungal agents can cause recurrent infections that affects approximately $5 \%$ of females who are getting infected at least four times a year $(3,4)$. The reason may because of some difficulties regarding an up growing incidence of resistant atypical Candida species, as well as significant patient distress, including sexual difficulties.

Studies revealed that the use of azole antifungal agents such as fluconazole has increased. This is mostly due to the increasing number of C. albicans infections (5). According to the literature, wide application of azoles lead to the most frequently encountered isolates resistant to these drugs. Most of these cases have higher azole minimum inhibitory concentrations (MICs) and the infections they cause are mostly difficult to cure (6). High recurrence rates of $C$. albicans vaginitis, cannot be successfully suppressed by fluconazole in long term therapies, and drug resistance is growing $(3,7)$. Pir1p is a protein with internal repeats, 36,459 Da molecular weight, 346 a.a. length and direct bounds to beta 1, 3-glucan in the cell wall of $C$. albicans $(8,9)$. This protein is O-glycosylated and $\mathrm{N}$-mannosylated and causes cell wall integrity in C. albicans (10).

\section{Objectives}

The current study aimed to investigate the relationship between the presence of Pirlp in the cell wall of $C$. albicans isolates and their resistance to fluconazole; the study examined overexpression of pir1 gene in 49 clinical C. albicans isolates with fluconazole -resistance. It is proposed that long time exposure of $C$.albicans to fluconazole affects the integrity of the cellular caused by overexpression of pir1 gene.

Copyright (C) 2015, Ahvaz Jundishapur University of Medical Sciences. This is an open-access article distributed under the terms of the Creative Commons Attribution-NonCommercial 4.0 International License (http://creativecommons.org/licenses/by-nc/4.0/) which permits copy and redistribute the material just in noncommercial usages, provided the original work is properly cited. 


\section{Patients and Methods}

The current study was conducted for six months on 250 females referring to gynecology clinic, Tehran, Iran. Recurrence was defined as two or more infections in a sixmonth period.

\subsection{Patient Population}

The inclusion criteria for the survey were married, 17 53 years old with symptoms of vaginal discharge and/or genital itching with recurrent vulvovaginal candidiasis; all patients were given multi agent antifungal therapy including fluconazole. Fifty-two C. albicans species isolated from clinical samples were identified and used for fluconazole susceptibility testing and overexpression of Pir1 gene in the cell wall of the isolates.

\subsection{Identification}

Candida albicans isolates were identified by standard methods such as germ tube and cornmeal agar test (HiMedia, Mumbai, India) (11).

\subsection{Antifungal Susceptibility Testing}

Susceptibility of C. albicans isolates to fluconazole was performed using CLSI protocol for disk diffusion testing, inhibition zone criteria for fluconazole included application of the $10 \mathrm{mg} / \mathrm{mL}$ fluconazole discs (Hi-Media, Mumbai, India) using aseptic technique (12); each plate was examined after $20-24$ hours of incubation at $37^{\circ} \mathrm{C}$ to measure inhibition zones diameter.

\subsection{Polymerase Chain Reaction Amplification to Identify Overexpression of pir1 Gene}

PCR amplification method, as a rapid and reliable method to identify C. albicans species, was applied to detect Pir1 overexpression gene. The PCR assay was performed with $1 \mu \mathrm{L}$ of test sample in a total reaction volume of 25 $\mu \mathrm{L}$ consisting of $2.5 \mu \mathrm{L} 10 \mathrm{X}$ PCR buffer, $1 \mathrm{~mL} 25 \mathrm{mM} \mathrm{MgCl}_{2}$, $1 \mathrm{~mL} 5 \mathrm{mM}$ dNTPs, $1 \mathrm{~mL}$ each primer $(0.25 \mathrm{pmol} / \mathrm{mL}$ ) (Forward: 5'-GCGAGTATTCTACACTTGTTAG and Reverse 5'-CGTGACAAATTCAATGACAC and $1.25 \mathrm{U}$ of Taq DNA polymerase and finally $16.25 \mathrm{~mL} \mathrm{ddH}_{2} \mathrm{O}$ was added. Thirty cycles of amplification were performed in thermal cycler. After initial denaturation of DNA at $95^{\circ} \mathrm{C}$ for five minutes, each cycle consisted of a denaturation step at $94^{\circ} \mathrm{C}$ for $30 \mathrm{sec}$ onds, an annealing step at $56^{\circ} \mathrm{C}$ for 30 seconds, an extension step at $72^{\circ} \mathrm{C}$ for one minute and a final extension step at $72^{\circ} \mathrm{C}$ for seven minutes following the last cycle. Appropriate negative and positive controls were included in each test running (8).

\section{Results and Discussion}

A total of 150 females referred to the center with recurring vulvovaginitis, of which only 52 had C. albicans vaginitis. Susceptibility testing to fluconazole was carried out on 52 C. albicans isolates. Of these, 49 (94\%) isolates showed resistance to fluconazole while $3(7 \%)$ were susceptible (Data not shown). According to the obtained results, the majority of C. albicans isolates were resistant to fluconazole and had an inhibition zone diameter below the selected breakpoint ( $<21 \mathrm{~mm}$ in the present study); these strains could be reported as resistant to fluconazole causes cell wall stress (13). Upon this stress, overexpression of cell wall proteins might be induced as an important compensatory feedback. Pirlp is responsible for cell wall maintenance, and the current study found its overexpression in the cell wall upon long term of fluconazole treatment. Since fluconazole treatment leads to no cure or temporary cure with recurrent one, it seems that this could indirectly affect cell wall integrity; for example, by long term fluconazole treatment compared with those of the females in initiating time of taking fluconazole, pir1p presence is different in cell wall construction by affecting frequent prescribed fluconazole. Long term fluconazole -treated C. albicans cells contain considerably high protein in their walls, suggesting severe alterations (9).

The $C$. albicans cell wall is a complex structure with major components of a $\beta-1,3-$ and $\beta$-1,6-glucan network and a number of proteins attached covalently and non-covalently to this network. The C. albicans cell wall plays important roles in growth and development, interactions with mammalian cells and tissues during infection and colonization as well as a primary protective role in shielding the cell against osmotic, chemical and biological harm. Pir1p seems to be only attached to the $\beta$-1,3-glucan covalently (8) to act as a glue to protect the yeast cell. A lot of data support the idea that the resistance of the yeast cells to fluconazole could be due to either a reduced level of drug uptake or an increased level of drug efflux (7). They could also be the result of changes in the ingredient of the yeast cell wall and cell membrane.

The current study identified an important cell wall protein induced by fluconazole stress and required for cell wall cross-linking and integrity (Pirlp). Pirlp is a unique structural protein of the C. albicans cell wall directly bound to $\beta$-1, 3-glucan which is essential to maintain the integrity of $C$. albicans cell wall. Overexpression of pirt gene is regulated by growth conditions such as $\mathrm{pH}$ (14), antifungal agents (9) and hypoxic causing a rigid barrier in the cell wall of C. albicans to defend the yeast (10). Additionally, the current survey revealed that the changes in the transcript levels of pir1-encoding gene when C. albicans is not challenged with fluconazole, predicted the directions of the changes in the agreement with Pir1 cell wall protein level upon treatment with fluconazole (Figure 1), supporting the concept that fluconazole compromises cell wall integrity. Therefore antifungal potential of the isolated was tested by disc diffusion method. Exposure to fluconazole increased the Pir1 protein and resistance to fluconazole and exposure led to a fall in uptake of fluconazole. A relationship between resistance to fluconazole and increased Pirigene expression was observed in C. albicans cells. 
Figure 1. PCR Analysis Employing for Pir1 Gene

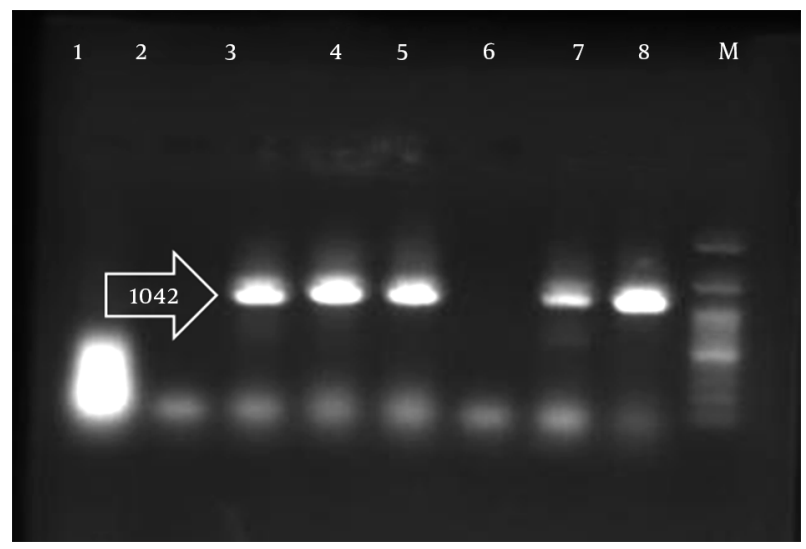

Lane 1, negative control; Lane 8, positive control; Lane M, the ladder; Lanes $2-7$ are samples. Pir1 gene with 1041 bp length was found in positive samples as $3,4,5$ and 7 .

In the current study, the overall prevalence of recurrent $C$. albicans vulvovaginal candidiasis resistant to fluconazole in a community setting was $94 \%$ which was similar to those of the studies conducted elsewhere with the rates approximately $\% 100$ (4). In vitro studies on the cell wall of fluconazole -resistant $C$. albicans strains showed high distribution of cell wall glucan-associated proteins (15). These results suggest that long term fluconazole treatment can affect fungal cell wall metabolism and structure which lead to fluconazole -resistant C. albicans vaginitis (16).

In conclusion, the study provided information on fluconazole susceptibility of vaginal C. albicans isolates in a gynecology clinic in Tehran, Iran. Since the majority of $C$. albicans isolates were resistant to fluconazole, the result was related to overexpression of Pir1p. The obtained results demonstrated the presence of Pirlp in the cell wall of $C$. albicans isolates of the study and it was found that fluconazole in long term therapies generates a rise in expression of Pir1 gene. Although the actual function of Pir1 is still unknown, it may be critical in the cell wall formation during the first steps of protoplast regeneration. Further researches are needed.

\section{Authors' Contributions}

All authors participated in the current research.

\section{Funding/Support}

This study was supported by Tarbiat Modares university, Tehran, Iran.

\section{References}

1. Sobel JD. Vaginitis. N Engl J Med. 1997;337(26):1896-903.

2. Sobel JD. Candida vulvovaginitis. Semin Dermatol.1996;15(1):17-28

3. Lynch ME, Sobel JD, Fidel PJ. Role of antifungal drug resistance in the pathogenesis of recurrent vulvovaginal candidiasis. J Med Vet Mycol.1996;34(5):337-9.

4. MacNeill C, Weisz J, Carey JC. Clinical resistance of recurrent Candida albicans vulvovaginitis to fluconazole in the presence and absence of in vitro resistance. J Reprod Med. 2003;48(2):63-8.

5. Bodey GP. Azole antifungal agents. Clin Infect Dis. 1992;14 Suppl 1:S161-9.

6. Lynch ME, Sobel JD. Comparative in vitro activity of antimycotic agents against pathogenic vaginal yeast isolates. J Med Vet Mycol. 1994;32(4):267-74.

7. Lupetti A, Danesi R, Campa M, Del Tacca M, Kelly S. Molecular basis of resistance to azole antifungals. Trends Mol Med. 2002;8(2):76-81.

8. Martinez AI, Castillo L, Garcera A, Elorza MV, Valentin E, Sentandreu R. Role of Pir1 in the construction of the Candida albicans cell wall. Microbiology. 2004;150(Pt 10):3151-61.

9. Sorgo AG, Heilmann CJ, Dekker HL, Bekker M, Brul S, de Koster $\mathrm{CG}$, et al. Effects of fluconazole on the secretome, the wall proteome, and wall integrity of the clinical fungus Candida albicans. Eukaryot Cell. 2011;10(8):1071-81.

10. Sosinska GJ, de Groot PW, Teixeira de Mattos MJ, Dekker HL, de Koster CG, Hellingwerf KJ, et al. Hypoxic conditions and iron restriction affect the cell-wall proteome of Candida albicans grown under vagina-simulative conditions. Microbiology.2008;154(Pt 2):510-20.

11. Segal E, Elad D. Candida species and Blastoschizomyces capitatus. Topley Wilson's Microbiol Microb Infect. 1998;4:423-60.

12. May JL, King A, Warren CA. Fluconazole disc diffusion testing for the routine laboratory. J Antimicrob Chemother. 1997;40(4):511-6.

13. Mohanty S, Xess I, Hasan F, Kapil A, Mittal S, Tolosa JE. Prevalence \& susceptibility to fluconazole of Candida species causing vulvovaginitis. Indian J Med Res. 2007;126(3):216-9.

14. Lotz H, Sohn K, Brunner H, Muhlschlegel FA, Rupp S. RBR1, a novel pH-regulated cell wall gene of Candida albicans, is repressed by RIM101 and activated by NRG1. Eukaryot Cell. 2004;3(3):776-84.

15. Angiolella L, Micocci MM, D'Alessio S, Girolamo A, Maras B, Cassone A. Identification of major glucan-associated cell wall proteins of Candida albicans and their role in fluconazole resistance. Antimicrob Agents Chemother. 2002;46(6):1688-94.

16. Hazen KC, Mandell G, Coleman E, Wu G. Influence of fluconazole at subinhibitory concentrations on cell surface hydrophobicity and phagocytosis of Candida albicans. FEMS Microbiol Lett. 2000;183(1):89-94. 